\title{
Estimation of salt intake and excretion in children in one region of Switzerland: A cross-sectional study
}

Magali Rios-Leyvraz ${ }^{1}$, Pascal Bovet ${ }^{1}$, Murielle Bochud ${ }^{1}$, Bernard Genin ${ }^{2,3}$, Michel Russo ${ }^{2}$, Michel F. Rossier $^{3,4}$, René Tabin ${ }^{2,3}$, Arnaud Chiolero ${ }^{1,5,6}$

\author{
Affiliations: \\ ${ }^{1}$ Institute of Social and Preventive Medicine (IUMSP), Lausanne University Hospital (CHUV), \\ Lausanne, Switzerland \\ ${ }^{2}$ Hospital Center of Valais Romand, Hospital of Valais, Sion, Switzerland \\ ${ }^{3}$ Faculty of Medicine, University of Geneva, Geneva, Switzerland \\ ${ }^{4}$ Central Institute of the Hospitals, Hospital of Valais, Sion, Switzerland \\ ${ }^{5}$ Institute of Primary Health Care (BIHAM), University of Bern, Bern, Switzerland \\ ${ }^{6}$ Department of Epidemiology, Biostatistics and Occupational Health, McGill University, Montreal, \\ Canada
}

ORCID: Magali Rios-Leyvraz: 0000-0003-0455-197X

Keywords: salt, sodium chloride, urinary excretion, children, adolescents, food frequency questionnaire, Switzerland 


\section{Summary}

Purpose: Salt intake among children in Switzerland is unknown. The objectives of this study were to determine salt excretion and to identify the main dietary sources of salt intake among children in one region of Switzerland.

Methods: We conducted a cross-sectional study using a convenient sample of children 6-16 years of age in Valais, Switzerland, between 2016 and 2018. All children visiting several regional health care providers and without any clinical condition that could affect sodium intake or excretion were eligible. Each child completed a 24-hour urine collection to assess salt excretion and two dietary questionnaires to assess dietary sources of salt intake. Weight and height were measured.

Results: Data was available on 94 children (55 boys and 39 girls; mean age: 10.5 years; age range: 616 years). The mean 24 -hour salt urinary excretion was $5.9 \mathrm{~g}$ (SD: 2.8 ; range: $0.8-16.0 ; 95 \%$ confidence interval (CI): $5.3-6.5)$. Two thirds (62\%) of the children had salt excretions above recommendations of maximum intake (i.e., $\geq 2 \mathrm{~g}$ per day for children up to 6 years of age and $\geq 5 \mathrm{~g}$ per day for children 7-16 years of age). The salt excretion tended to be higher during the weekend (6.0 g, 95\% CI: 5.4-6.6) than during the week (5.4 g, 95\% CI: 4.3-6.7). The main sources of salt intake were pastas, potatoes, and rice $(23 \%$ of total salt intake), pastries $(16 \%)$, bread $(16 \%)$, and cured meats $(10 \%)$. One child out of three (34\%) added salt to their plate at the table.

Conclusions: Salt intake in children in one region of Switzerland was high. Our findings suggest that salt intake in children could be reduced by lowering salt content in commonly eaten foods.

Trial registration number: NCT02900261 


\section{Introduction}

High salt intake has been estimated to cause 1.65 million deaths from cardiovascular diseases per year [1], mainly due to its effect on blood pressure. High salt intake has been associated with elevated blood pressure in adults [2-4], as well as in children [5]. There is also growing evidence that blood pressure tracks from childhood to adulthood [6-9] and that elevated blood pressure can cause vascular damage starting at a young age $[8,9]$. Moreover, childhood and adolescence are key periods of an individual's life during which dietary habits are formed [10]. This suggests that limiting salt intake already during childhood has the potential to prevent lifelong hypertension and its associated consequences $[11,12]$. Assessing the level of salt intake in children has therefore clinical and public health relevance.

Worldwide, adults consume approximately $10 \mathrm{~g}$ of salt (i.e. sodium chloride, $\mathrm{NaCl}$ ) per day [1], which is far above the maximum of $5 \mathrm{~g}$ recommended by the World Health Organization [13]. In a national survey conducted in Switzerland among 1'448 adults in 2010-2011, the 24-hour urine excretion of salt was $10 \mathrm{~g}$ in men and $8 \mathrm{~g}$ in women [14]. Very few data on salt intake exists among children worldwide [15]. In Switzerland, the salt intake in children is unknown. One reason for this lack of information is notably the difficulty of assessing salt intake. The gold standard method to estimate salt intake is to measure sodium excretion in a 24-hour urine collection [16-18], which is however challenging to perform, especially in children [19-21].

Taking advantage of a study in which a 24-hour urine sample was collected, we determined the salt excretion and identified the main dietary sources of salt intake among children aged 6 to 16 years old in one region of Switzerland. 


\section{Materials and methods}

\section{Study design}

This study was cross-sectional with a convenient sample of outpatient children between 6 and 16 years of age. All children visiting various regional health care providers were eligible. Children with any conditions potentially altering the consumption and excretion of sodium (e.g., chronic renal diseases), taking medication that alters sodium excretion (e.g., diuretics), intravenous infusion during data collection, or insufficient knowledge of the local language were not eligible. Children were recruited at the Hospital of Valais, Sion, Switzerland, and at several pediatric and primary care facilities in Valais, Switzerland. The primary goal of this study was to compare 24-hour urine collections with urinary spots to estimate sodium excretion in children (see ClinicalTrias.gov, study number: NCT02900261). The secondary goal of this study, and the topic of this paper, was to assess salt excretion and intake in a sample of children in Switzerland.

\section{Data collection}

Upon enrolment, the children, in a non-fasting state, were weighed with a weighing scale and measured with a wall mounted stadiometer in light clothes and without shoes by a trained nurse or research assistant. Blood pressure was measured in a calm and temperate room, after 3 minutes of seated rest, on the right arm, and with an appropriate sized cuff. Blood pressure was measured up to 3 times.

The participants received all the material for the urine collection, which they did at home on the day of their choice. In order to ensure a complete collection, written and oral instructions were given to the participants and their parents and special collection pots were provided. The $24 \mathrm{~h}$ urine collection started on the evening of day 1 . The participants emptied their bladder before going to bed, discarded the urine and noted the time as the start of the collection. The collection was then conducted for 24 hour until the 
evening of the day 2. All urine samples were collected in the same container. Children and parents were instructed to store the urine samples in closed containers in the fridge between 4 and $8^{\circ} \mathrm{C}$. Urine samples were kept at home no more than 2 days before being brought to the laboratory where urine samples were immediately placed in a freezer at $-20^{\circ} \mathrm{C}$ until analysis. The sodium and creatinine levels and the volumes of the urine samples were measured at the Sion Hospital laboratory. Sodium concentration was measured with ion-selective electrodes and creatinine concentration with the Jaffe colorimetric method [22], using a Cobas ${ }^{\circledR} 501$ analyzer.

The parents completed a short questionnaire on the socio-demographic situation of the family. The children, with the help of their parents if necessary, completed two non-quantitative (i.e. without portion sizes) food frequency questionnaires, on the day prior (day 1) and on the day of (day 2) the 24-hour urine collection. The questionnaires contained foods and dishes commonly eaten in Switzerland and were adapted from previously used questionnaires $[7,23,24]$ (see Supplementary Material S1). As a small percentage of salt intake is excreted in sweat [25-27], the questionnaires also assessed physical activity during the urine collection. The questionnaire was pre-tested with two children to ensure that the questions were well understood.

\section{Ethical considerations}

The survey protocol was approved by the Ethics Committee of Canton de Vaud, Switzerland (CERVD, identification number: 2015-01178). Written consent was obtained from one of the parents (or legal guardian) and oral consent of the child. For children above 14 years of age, written consent of the child was obtained in addition. All children in the study received a backpack, a watch and a pen to thank them for their participation. 


\section{Calculations}

The 24-hour urinary salt excretion was calculated by multiplying the sodium (Na) concentration (mmol/L) in the 24 -hour urine sample by 0.0575 to transform to salt $(\mathrm{NaCl})$ concentration $(\mathrm{g} / \mathrm{L})$, and then multiplying it with the volume of the 24-hour urine collection (L) and by the duration of the collection (as a fraction of 24 hours) to obtain the total salt ( $\mathrm{NaCl}$ ) excretion in the 24-hour urine sample (g/day). Similarly to the 24-hour salt excretion, the 24 -hour creatinine excretion was calculated by multiplying the creatinine concentration $(\mathrm{mmol} / \mathrm{L})$ in the 24-hour urine sample by the total volume of the sample (L) and by the duration of the collection (as a fraction of 24 hours). A 24-hour creatinine excretion of less than $0.1 \mathrm{mmol}$ per $\mathrm{kg}$ of body weight per day was considered an indication of incomplete 24-hour urine collection [28]. The 24-hour creatinine excretion of incomplete urine collections were corrected to correspond to $0.1 \mathrm{mmol}$ creatinine per $\mathrm{kg}$ of body weight per day. The 24hour salt excretion of these incomplete collections was adjusted using the same correction factor.

\section{Statistical analysis}

Analyses were conducted to assess how sex, age, weight status, nationality, parents' education, completeness of 24-hour urine collection, day of the week of the collection and physical activity level during the collection were associated with the 24-hour salt $(\mathrm{NaCl})$ excretions. Following recommendations published in Switzerland [29], a 24-hour urine salt excretion below $1 \mathrm{~g}$ was considered as low and a 24-hour urine salt excretion above $2 \mathrm{~g}$ for children of 6 years of age and above $5 \mathrm{~g}$ for children between 7 and 16 years of age was considered as high.

Salt $(\mathrm{NaCl})$ intake was estimated using the average estimates from the two questionnaires on the day prior to and on the day of the urine collection. The amount of salt $(\mathrm{g})$ provided by each food category 
mentioned in the questionnaire was based on the salt concentrations (g per $100 \mathrm{~g}$ food) in the Swiss Food Composition database [30] and the usual portion sizes in Switzerland [31].

Body mass index (BMI) was calculated by dividing weight $(\mathrm{kg})$ by the squared height $(\mathrm{m})$. BMI zscores were based on the reference values from the 2000 Centers for Disease Control and Prevention (CDC) [32] and a score equal or above 1 was considered as overweight. Results are presented as percentages, means, standard deviations $( \pm \mathrm{SD})$ and $95 \%$ confidence interval $(95 \% \mathrm{CI})$. Salt excretion and intake from the urine collection and the questionnaires were compared using the Pearson correlation. Statistical analyses were conducted with R (version 3.3.1) and R Analytic Flow (version 3.0.6).

\section{Results}

\section{Participants characteristics}

A total of 101 children were recruited between September 2016 and February 2018 and 94 were able to collect a 24-hour urine sample. The characteristics of these children are shown in Table 1. The characteristics did not differ between boys and girls. Out of the 94 children with a 24 -hour urine collection, 8 had an incomplete 24 -hour collection according to the creatinine excretion in the 24-hour urine sample.

\section{Salt excretion}

The mean salt excretion in the children was 5.9 g per day (SD: 2.8; range: $0.8-16.0$; 95\% CI: 5.3-6.5). Almost two thirds of the children $(62 \%, n=58)$ had salt excretion above the age-specific recommendations. The salt excretion distribution is shown in Figure 1 and the salt excretions by subgroups are shown in Table 2. Children of male sex, older age, non-Swiss nationality, and with parents with higher education tended to have higher salt excretions. Salt excretion was lower in creatinine- 
corrected incomplete 24-hour urine collections than in complete urine collections (3.0 g, 95\% CI: 1.1 5.0 versus $6.1 \mathrm{~g}, 95 \% \mathrm{CI}: 5.5-6.7)$. Most of the 24 -hour urine samples were collected during the weekend (77.7\%), and 24-hour urinary salt excretions tended to be higher in collections during week-ends days than in collections during week days (6.0 g, 95\% CI: 5.4-6.6, vs 5.5 g, 95\% CI: 4.3-6.7). Physical activity was not associated with 24-hour urinary salt excretion.

\section{Questionnaires}

The salt intake estimates from the dietary questionnaires were higher than the salt excretion measured in the 24-hour urine collection (24-hour urine: $5.9 \mathrm{~g}$, 95\% CI 5.3-6.5; questionnaire day 1: $6.8 \mathrm{~g}, 95 \%$ CI 6.3-7.2; questionnaire day 2: 6.7g, 95\% CI 6.2-7.2; average of questionnaires days 1 and 2: $6.7 \mathrm{~g}$, 95\% CI 6.3-7.1). The correlation between the 24-hour urine salt excretion and salt intake estimated from the questionnaires was relatively low $(\mathrm{r}=0.25)$.

The main sources of salt intake are shown in Figure 2. The four food groups that provided the most salt to the diet were: 1$)$ cooked (and salted) pastas, potatoes, and rice (1.4 g salt/day, $23.2 \%$ of total salt intake); 2$)$ pastries ( $1.0 \mathrm{~g}$ salt /day, $16.3 \%$ of total salt intake); 3$)$ bread (1.0 g salt/day, $16.2 \%$ of total salt intake); and 4) cured meats ( $0.6 \mathrm{~g}$ salt/day, $10.3 \%$ of total salt intake).

Over the two days of data collection, $33.7 \%$ of the children added salt to the table, $17.8 \%$ ate at a restaurant, $5.0 \%$ ate at a fast food restaurant, and $19.8 \%$ ate ready-to-eat dishes. Children who added salt to the table tended to have higher 24-hour salt urinary excretion than children who did not $(6.1 \mathrm{~g}$, 95\% CI: 5.2-7.0, vs $5.6 \mathrm{~g}, 95 \% \mathrm{CI}: 4.9-6.2)$, as well as children who ate at a restaurant $(6.5 \mathrm{~g}, 95 \% \mathrm{CI}$ : 5.5-7.6, vs 5.5 g, 95\% CI: 4.9-6.1), and those who ate ready-to-eat dishes (6.6 g, 95\% CI: 5.6-7.7, vs $5.5 \mathrm{~g}, 95 \% \mathrm{CI}: 4.9-6.1)$. 


\section{Discussion}

\section{Summary of findings}

To our knowledge, this study is the first to assess salt excretion in children in one region of Switzerland using the golden standard, i.e., a 24-hour urine collection. The salt excretion in our sample of children was high with a majority of children above intake recommendations. The main sources of salt intake were pastas, potatoes and rice, pastries, bread, and cured meats.

In Europe, there is little data on the salt intake in children, but the few available studies suggests that intake is high, similarly to adults [33]. In Spain, a study conducted in 2014 with 205 children aged 711 years old and using 24-h urine collections showed a salt intake of 7.8 g per day [34]. In Portugal, a study conducted in 2014 among 163 children between 8 and 10 years of age who collected a $24 \mathrm{~h}$ urine sample showed a salt intake of $6.6 \mathrm{~g}$ per day [35]. In Italy, a study included 1424 children between 6 and 18 years of age in Italy who collected a $24 \mathrm{~h}$ urine sample and found a salt intake of $7.1 \mathrm{~g}$ per day [36]. In Austria, a study conducted in 2010-2012 among 392 boys and girls between 7 and 14 years of age with casual urinary spots showed a salt intake of 6.2 and $7.1 \mathrm{~g}$ per day, respectively [37]. In the United States, using data from 2'142 children 6-18 years to the 2011-2012 NHANES survey, based on a 24-hour diet recall, the salt intake was $8.1 \mathrm{~g}$ per day [38]. In Switzerland, a national nutrition survey conducted in 2010-2011 among adults showed that salt excretion was on average $9.9 \mathrm{~g}$ salt per day [14]. In our study, the salt excretion of children aged 6-16 years was $5.9 \mathrm{~g}$ per day, which is lower than in Swiss adults, and which is probably lower than the actual salt intake in the general Swiss population of children.

Our analysis of salt intake derived from various foods using a non-quantitative food frequency questionnaire showed that there is, on one hand, foods that contain high concentration of salt, but that are consumed in relatively small amounts, and, on the other hand, foods that contain low-moderate 
concentrations of salt, but that are eaten in large amounts. In our study, the food items with the highest salt concentration were cured meats, processed fish, cheese, pastries and bread, similarly to other European countries $[39,40]$. In contrast, the foods that provided the largest amount of salt to the diet in our study were cooked (and salted) pastas, potatoes, and rice; pastries; bread, and; cured meats. This is similar with findings from other countries in Europe [41], where, despite regional and cultural differences, the foods that provide the highest amounts of salt are grain-based products (including bread), meat products, and dairy products [41]. Our findings suggest that, in order to reduce salt intake in children in Switzerland, salt content should not only be reduced in foods with high salt concentrations, but also in foods with moderate salt concentrations that are eaten in large amounts, such as bread and pastries.

There are two key strategies to reduce sodium intake at the population level: 1) voluntary or mandatory reformulation strategies to reduce salt content of foods and 2) education and behavior change communication of consumers [42]. Reformulation policies to reduce salt in manufactured foods can be highly cost-effective [43]. In our study, salt intake was provided mainly from commonly eaten foods, suggesting that to reduce salt intake in children voluntary or mandatory reformulation strategies to reduce the salt content of these foods would be advisable. Between 2008 and 2016, voluntary reformulation was already used in Switzerland to progressively reduce by $16 \%$ salt in breads [44]. This strategy could be used again to further reduce salt content of breads and expanded to other commonly eaten foods. In addition, the support of behavior change campaigns and consumer education would be beneficial.

\section{Strengths and limitations}

The main strength of our study is that salt excretion was estimated using 24-hour urine collection. The completeness of the urine collections was assessed and incomplete collections were corrected. In 
addition, a dietary questionnaire was completed on the day prior to and of the urine collection, allowing the determination of main sources of salt intake in the sample in the same children in parallel to the urine collection.

Our study has however several limitations. First, selection of participants was based on convenience sampling and in a selected region of Switzerland. Indeed, the study was not primarily designed to estimate the salt intake among children in Switzerland. To estimate salt intake with more confidence at a regional or national level, we recommend to conduct a larger study using a population- or schoolbased sampling. Second, our study might have over- or under-estimated the actual salt intakes and excretions. Over-estimation of salt excretion could have been caused by the fact that the urine collection was often done during the week-end $(79 \%)$ and that the excretion during week-end days tended to be higher than during week days. Under-estimation was more likely due to several reasons, such as, measurement bias (salt urinary excretion is equal to $80-95 \%$ of the salt intake [45-47]), participation bias (people who are willing to participate in nutrition studies tend to be more health-conscious than those who do not and therefore possibly consume lower amounts of salt), and the Hawthorne effect (participants might have reduced their salt intake during the urine collection as they knew that salt excretion was going to be measured). To more precisely quantify the bias in the estimates, a quantitative bias analysis would be warranted [48]. However, this is beyond the scope of this paper. Third, there are limitations with the questionnaire. The salt content of the foods were not measured directly, but were taken from the Swiss Food Composition Database [30]. Moreover, the salt intake estimates from the questionnaires could also have been over-estimated, since the portion sizes were not recorded, but based on the standard portion sizes in Switzerland for adults [31], which are probably bigger than the portions eaten by the children in our study. The correlation between the sodium intake estimates from our questionnaire and from the 24-hour urine collections was low $(\mathrm{r}=0.25)$, yet close to correlations found between salt excretion and salt intake estimates from food frequency questionnaires in adults [49]. This 
low correlation could also be explained by a reporting bias (i.e. difference between actual intake and reported intakes), as well as infradian fluctuations in urinary salt excretion that happen even at constant salt intake [47]. In addition, the salt excretion was estimated based on only one 24-h urine collection. Repeated 24-h urine collections would have been better to have more confidence in our estimates [50].

Finally, the way we have defined high salt intake (i.e. $\geq 2$ g per day for children between 1 and 6 years of age and $\geq 5$ g per day for children above 7 years of age) was arbitrary, following local recommendations published in Switzerland [29]. This definition is nevertheless in-line with the maximum of $5 \mathrm{~g} /$ day recommended for adults by the WHO [13], at least for children between 7 and 16 years of age. There are several recommendations for salt intake in children (see Supplementary Material S2) and there is no universal consensus about optimal or high salt intake in children [51]. Recommendations are indeed based on expert opinions but not on high quality evidence. In efforts to determine the optimal intake of various nutrients, including sodium, based on scientific evidence, the European Food Security Authority (EFSA) is currently conducting a review of the evidence [33].

\section{Conclusions}

The salt intake in a sample of children in one region of Switzerland was high. Limiting salt intake starting in childhood could help for the primordial prevention of hypertension and cardiovascular diseases. As dietary habits are formed in large part during childhood, it is important to accustom children to lower salt intake early on. Reducing salt content of selected frequently eaten foods, such as bread, could be one strategy to reduce salt intake in children in Switzerland. 
Supplementary files: Food frequency questionnaire

Funding sources: This work was funded by the Swiss Federal Food Safety and Veterinary Office (FSVO) (funding reference number 5.15.03). The funder had no role in the protocol development, data collection, data analysis, interpretation or publication of the results.

Conflicts of interest: The authors declare no conflicts of interest.

Acknowledgments: We thank the participants and their parents for taking part in the study and Mrs Marie-France Rudaz and her team for the laboratory analyses.

Data sharing: The data are available upon request to the corresponding author.

Correspondence: Magali Rios-Leyvraz, route de la Corniche 10, 1010 Lausanne, Switzerland, +41 21 31494 87, magali.leyvraz@chuv.ch 


\section{References}

1. Mozaffarian D, Fahimi S, Singh GM, Micha R, Khatibzadeh S, Engell RE, Lim S, Danaei G, Ezzati M, Powles J, Global Burden of Diseases N, Chronic Diseases Expert G (2014) Global sodium consumption and death from cardiovascular causes. N Engl J Med 371 (7):624-634. doi:10.1056/NEJMoa1304127

2. He FJ, Li J, Macgregor GA (2013) Effect of longer term modest salt reduction on blood pressure: Cochrane systematic review and meta-analysis of randomised trials. BMJ 346:f1325. doi:10.1136/bmj.f1325

3. Graudal NA, Hubeck-Graudal T, Jürgens G (2012) Effects of low-sodium diet vs. high-sodium diet on blood pressure, renin, aldosterone, catecholamines, cholesterol, and triglyceride (Cochrane Review). Am J Hypertens 25 (1):1-15. doi:10.1038/ajh.2011.210

4. Meneton P, Jeunemaitre X, de Wardener HE, MacGregor GA (2005) Links between dietary salt intake, renal salt handling, blood pressure, and cardiovascular diseases. Physiol Rev 85 (2):679-715. doi:10.1152/physrev.00056.2003

5. Leyvraz M, Chatelan A, da Costa BR, Taffe P, Paradis G, Bovet P, Bochud M, Chiolero A (2018) Sodium intake and blood pressure in children and adolescents: A systematic review and meta-analysis of experimental and observational studies. Int J Epidemiol (dyy121):1-15. doi:https://doi.org/10.1093/ije/dyy121

6. Chen X, Wang Y (2008) Tracking of blood pressure from childhood to adulthood: a systematic review and meta-regression analysis. Circulation $117 \quad$ (25):3171-3180. doi:10.1161/CIRCULATIONAHA.107.730366 
7. Chiolero A, Cachat F, Burnier M, Paccaud F, Bovet P (2007) Prevalence of hypertension in schoolchildren based on repeated measurements and association with overweight. J Hypertens 25 (11):2209-2217. doi:10.1097/HJH.0b013e3282ef48b2

8. McCrindle BW (2010) Assessment and management of hypertension in children and adolescents. Nat Rev Cardiol 7 (3):155-163. doi:10.1038/nrcardio.2009.231

9. Chiolero A, Bovet P, Paradis G (2013) Screening for elevated blood pressure in children and adolescents: a critical appraisal. JAMA Pediatr 167 (3):266-273. doi:10.1001/jamapediatrics.2013.438 10. Lipsky LM, Haynie DL, Liu D, Chaurasia A, Gee B, Li K, Iannotti RJ, Simons-Morton B (2015) Trajectories of eating behaviors in a nationally representative cohort of U.S. adolescents during the transition to young adulthood. Int J Behav Nutr Phys Act 12:138. doi:10.1186/s12966-015-0298-X

11. Labarthe DR (1999) Prevention of cardiovascular risk factors in the first place. Prev Med 29 (6 Pt 2):S72-78. doi:10.1006/pmed.1999.0539

12. Gillman MW (2015) Primordial prevention of cardiovascular disease. Circulation 131 (7):599-601. doi:10.1161/CIRCULATIONAHA.115.014849

13. World Health Organization (2012) Guideline: Sodium intake for adults and children. World Health Organization (WHO), Geneva

14. Chappuis A, Bochud M, Glatz N, Vuistiner P, Paccaud F, Burnier M (2011) Swiss survey on salt intake: main results. Service de Néphrologie et Institut Universitaire de Médecine Sociale et Préventive, Centre Hospitalier Universitaire Vaudois (CHUV), Lausanne, Suisse

15. Olsen MH, Angell SY, Asma S, Boutouyrie P, Burger D, Chirinos JA, Damasceno A, Delles C, Gimenez-Roqueplo AP, Hering D, Lopez-Jaramillo P, Martinez F, Perkovic V, Rietzschel ER, Schillaci G, Schutte AE, Scuteri A, Sharman JE, Wachtell K, Wang JG (2016) A call to action and a lifecourse 
strategy to address the global burden of raised blood pressure on current and future generations: the Lancet Commission on hypertension. Lancet 388 (10060):2665-2712. doi:10.1016/S0140$6736(16) 31134-5$

16. Grimes CA, Riddell LJ, Campbell KJ, Nowson CA (2013) Dietary salt intake, sugar-sweetened beverage consumption, and obesity risk. Pediatrics 131 (1):14-21. doi:10.1542/peds.2012-1628

17. Tian N, Zhang Z, Loustalot F, Yang Q, Cogswell ME (2013) Sodium and potassium intakes among US infants and preschool children, 2003-2010. Am J Clin Nutr 98 (4):1113-1122. doi:10.3945/ajen.113.060012

18. Cogswell ME, Wang CY, Chen TC, Pfeiffer CM, Elliott P, Gillespie CD, Carriquiry AL, Sempos CT, Liu K, Perrine CG, Swanson CA, Caldwell KL, Loria CM (2013) Validity of predictive equations for 24-h urinary sodium excretion in adults aged 18-39 y. Am J Clin Nutr 98 (6):1502-1513. doi:10.3945/ajen.113.059436

19. Cooper R, Liu K, Trevisan M, Miller W, Stamler J (1983) Urinary sodium excretion and blood pressure in children: absence of a reproducible association. Hypertension 5 (1):135-139

20. Cooper R, Soltero I, Liu K, Berkson D, Levinson S, Stamler J (1980) The association between urinary sodium excretion and blood pressure in children. Circulation 62 (1):97-104

21. Liu K, Cooper R, Soltero I, Stamler J (1979) Variability in 24-hour urine sodium excretion in children. Hypertension 1 (6):631-636

22. Jaffé M (1886) Ueber den Niederschlag, welchen Pikrinsäure in normalem Harn erzeugt und über eine neue Reaktion des Kreatinins. Z Physiol Chem 10:391-400

23. Bühler E, Lachenmeier DW, Schlegel K, Winkler G (2014) Development of a tool to assess the caffeine intake among teenagers and young adults. Ernaehrungs Umschau 4:58-63 
24. Ebenegger V, Marques-Vidal P, Barral J, Kriemler S, Puder JJ, Nydegger A (2010) Eating habits of preschool children with high migrant status in Switzerland according to a new food frequency questionnaire. Nutr Res 30 (2):104-109. doi:10.1016/j.nutres.2010.01.006

25. Palacios C, Wigertz K, Martin BR, Jackman L, Pratt JH, Peacock M, McCabe G, Weaver CM (2004) Sodium retention in black and white female adolescents in response to salt intake. J Clin Endocrinol Metab 89 (4):1858-1863. doi:10.1210/jc.2003-031446

26. Cogswell ME, Maalouf J, Elliott P, Loria CM, Patel S, Bowman BA (2015) Use of urine biomarkers to assess sodium intake: challenges and opportunities. Annu Rev Nutr 35:349-387. doi:10.1146/annurev-nutr-071714-034322

27. Bates GP, Miller VS (2008) Sweat rate and sodium loss during work in the heat. J Occup Med Toxicol 3:4. doi:10.1186/1745-6673-3-4

28. Remer T, Neubert A, Maser-Gluth C (2002) Anthropometry-based reference values for 24-h urinary creatinine excretion during growth and their use in endocrine and nutritional research. Am J Clin Nutr $75(3): 561-569$

29. Lava SAG, Bucher BS, Bianchettia MG, Simonetti GD (2014) Consommation de sel chez les enfants. Forum Med Suisse 14 (10):191-194

30. Federal Food Safety and Veterinary Office Swiss Food Composition Database V5.2.

31. Morabia A, Bernstein M, Kumanyika S, Sorenson A, Mabiala I, Prodolliet B, Rolfo I, Luong BL (1994) Développement et validation d'un questionnaire alimentaire semi-quantitatif à partir d'une enquête de population. Soz Praventivmed 39 (6):345-369 
32. Kuczmarski RJ, Ogden CL, Guo SS, Grummer-Strawn LM, Flegal KM, Mei Z, Wei R, Curtin LR, Roche AF, Johnson CL (2002) 2000 CDC Growth Charts for the United States: methods and development. Vital Health Stat 11 (246):1-190

33. European Food Safety Authority (EFSA) (2017) Public consultation on the scientific opinion on dietary reference values for sodium (intermediate draft) and related protocol.

34. Aparicio A, Rodríguez-Rodríguez E, Cuadrado-Soto E, Navia B, López-Sobaler AM, Ortega RM (2015) Estimation of salt intake assessed by urinary excretion of sodium over $24 \mathrm{~h}$ in Spanish subjects aged 7-11 years. Eur J Nutr 56 (1):171-178

35. Oliveira AC, Padrao P, Moreira A, Pinto M, Neto M, Santos T, Madureira J, Fernandes Ede O, Graca P, Breda J, Moreira P (2015) Potassium urinary excretion and dietary intake: a cross-sectional analysis in 8-10 year-old children. BMC Pediatr 15:60. doi:10.1186/s12887-015-0374-z

36. Campanozzi A, Avallone S, Barbato A, Iacone R, Russo O, De Filippo G, D'Angelo G, Pensabene L, Malamisura B, Cecere G, Micillo M, Francavilla R, Tetro A, Lombardi G, Tonelli L, Castellucci G, Ferraro L, Di Biase R, Lezo A, Salvatore S, Paoletti S, Siani A, Galeone D, Strazzullo P (2015) High sodium and low potassium intake among Italian children: relationship with age, body mass and blood pressure. PLoS One 10 (4):e0121183. doi:10.1371/journal.pone.0121183

37. Elmadfa I, Hasenegger V, Wagner K, Putz P, Weidl NM, Wottawa D, Kuen T, Seiringer G, Meyer AK, Sturtzel B, Kiefer I, Zilberszac A, Sgarabottolo V, Meidlinger B (2012) Österreichischer Ernährungsbericht 2012. Vienna

38. Quader ZS, Gillespie C, Sliwa SA, Ahuja JK, Burdg JP, Moshfegh A, Pehrsson PR, Gunn JP, Mugavero K, Cogswell ME (2017) Sodium Intake among US School-Aged Children: National Health and Nutrition Examination Survey, 2011-2012. J Acad Nutr Diet 117 (1):39-47 e35. doi:10.1016/j.jand.2016.09.010 
39. Ni Mhurchu C, Capelin C, Dunford EK, Webster JL, Neal BC, Jebb SA (2011) Sodium content of processed foods in the United Kingdom: analysis of 44,000 foods purchased by 21,000 households. Am J Clin Nutr 93 (3):594-600. doi:10.3945/ajen.110.004481

40. Capuano E, der Veer G, Verheijen PJJ, Heenan SP, van de Laak LFJ, Koopmans HBM, van Ruth SM (2013) Comparison of a sodium-based and a chloride-based approach for the determination of sodium chloride content of processed foods in the Netherlands. J Food Compost Anal 31 (1):129-136

41. Kloss L, Meyer JD, Graeve L, Vetter W (2015) Sodium intake and its reduction by food reformulation in the European Union - A review. NJS Journal 1:9-19

42. World Health Organization (2013) Global action plan for the prevention and control of noncommunicable diseases 2013-2020. World Health Organization, Geneva

43. Wang G, Labarthe D (2011) The cost-effectiveness of interventions designed to reduce sodium intake. J Hypertens 29 (9):1693-1699. doi:10.1097/HJH.0b013e328349ba18

44. Swiss Federal Food Safety and Veterinary Office (2015) Moins de sel dans le pain en Suisse

45. Schachter J, Harper PH, Radin ME, Caggiula AW, McDonald RH, Diven WF (1980) Comparison of sodium and potassium intake with excretion. Hypertension 2 (5):695-699

46. Holbrook JT, Patterson KY, Bodner JE, Douglas LW, Veillon C, Kelsay JL, Mertz W, Smith JC, Jr. (1984) Sodium and potassium intake and balance in adults consuming self-selected diets. Am J Clin Nutr 40 (4):786-793

47. Rakova N, Juttner K, Dahlmann A, Schroder A, Linz P, Kopp C, Rauh M, Goller U, Beck L, Agureev A, Vassilieva G, Lenkova L, Johannes B, Wabel P, Moissl U, Vienken J, Gerzer R, Eckardt KU, Muller DN, Kirsch K, Morukov B, Luft FC, Titze J (2013) Long-term space flight simulation 
reveals infradian rhythmicity in human $\mathrm{Na}(+)$ balance. Cell Metab 17 (1):125-131. doi:10.1016/j.cmet.2012.11.013

48. Lash TL, Fox MP, MacLehose RF, Maldonado G, McCandless LC, Greenland S (2014) Good practices for quantitative bias analysis. Int J Epidemiol 43 (6):1969-1985. doi:10.1093/ije/dyu149

49. McLean RM, Farmer VL, Nettleton A, Cameron CM, Cook NR, Campbell NRC, Consortium T (2017) Assessment of dietary sodium intake using a food frequency questionnaire and 24-hour urinary sodium excretion: a systematic literature review. J Clin Hypertens (Greenwich) 19 (12):1214-1230. doi: $10.1111 /$ jch. 13148

50. Olde Engberink RHG, van den Hoek TC, van Noordenne ND, van den Born BH, Peters-Sengers H, Vogt L (2017) Use of a single baseline versus multiyear 24-hour urine collection for estimation of longterm sodium intake and associated cardiovascular and renal risk. Circulation 136 (10):917-926. doi:10.1161/CIRCULATIONAHA.117.029028

51. Mente A, O'Donnell M, Rangarajan S, Dagenais G, Lear S, McQueen M, Diaz R, Avezum A, LopezJaramillo P, Lanas F, Li W, Lu Y, Yi S, Rensheng L, Iqbal R, Mony P, Yusuf R, Yusoff K, Szuba A, Oguz A, Rosengren A, Bahonar A, Yusufali A, Schutte AE, Chifamba J, Mann JF, Anand SS, Teo K, Yusuf S, Pure E, Investigators OT (2016) Associations of urinary sodium excretion with cardiovascular events in individuals with and without hypertension: a pooled analysis of data from four studies. Lancet 388 (10043):465-475. doi:10.1016/S0140-6736(16)30467-6 


\section{Captions of tables and figures}

Table 1 Characteristics of the participants with complete 24-hour urine collection $(n=94)$

\begin{tabular}{lccc}
\hline Characteristics & $\begin{array}{c}\text { Means or } \\
\text { Percentages }\end{array}$ & SD & Range \\
\hline Age (years) & 10.6 & 2.9 & $6-16$ \\
Female (\%) & $41.5 \%$ & - & - \\
Height (cm) & 142 & 17 & $113-186$ \\
Weight (kg) & 36.2 & 14.2 & $17.4-88.0$ \\
Body mass index $\left(\mathrm{kg} / \mathrm{m}^{2}\right)$ & 17.4 & 3.8 & $12.5-37.2$ \\
Overweight (\%) & $16.0 \%$ & - & - \\
Systolic blood pressure (mmHg) & 109 & 13 & $75-142$ \\
Diastolic blood pressure (mmHg) & 62 & 10 & $40-99$ \\
Swiss nationality (\%) & $89.1 \%$ & - & - \\
Parent with tertiary education (\%) & $66.3 \%$ & - & - \\
\hline
\end{tabular}


Fig. 1 Histogram of 24-hour salt excretion (from 24h urine collection)

This figure shows the distribution of the $24 \mathrm{~h}$ salt excretion in our sample. Salt excretions ranged from 0.8 to $16.0 \mathrm{~g}$ per day. The mean salt excretion in the children was $5.9 \mathrm{~g}$ per day and ranged from 0.8 to $16.0 \mathrm{~g}$ per day. The majority of the children had a salt excretion above the recommended maximum salt intake. Legend: Black line: Kernel density curve; blue line: recommended minimum salt intake (i.e. 1 g per day); red line: recommended maximum salt intake (i.e. 5 g per day).

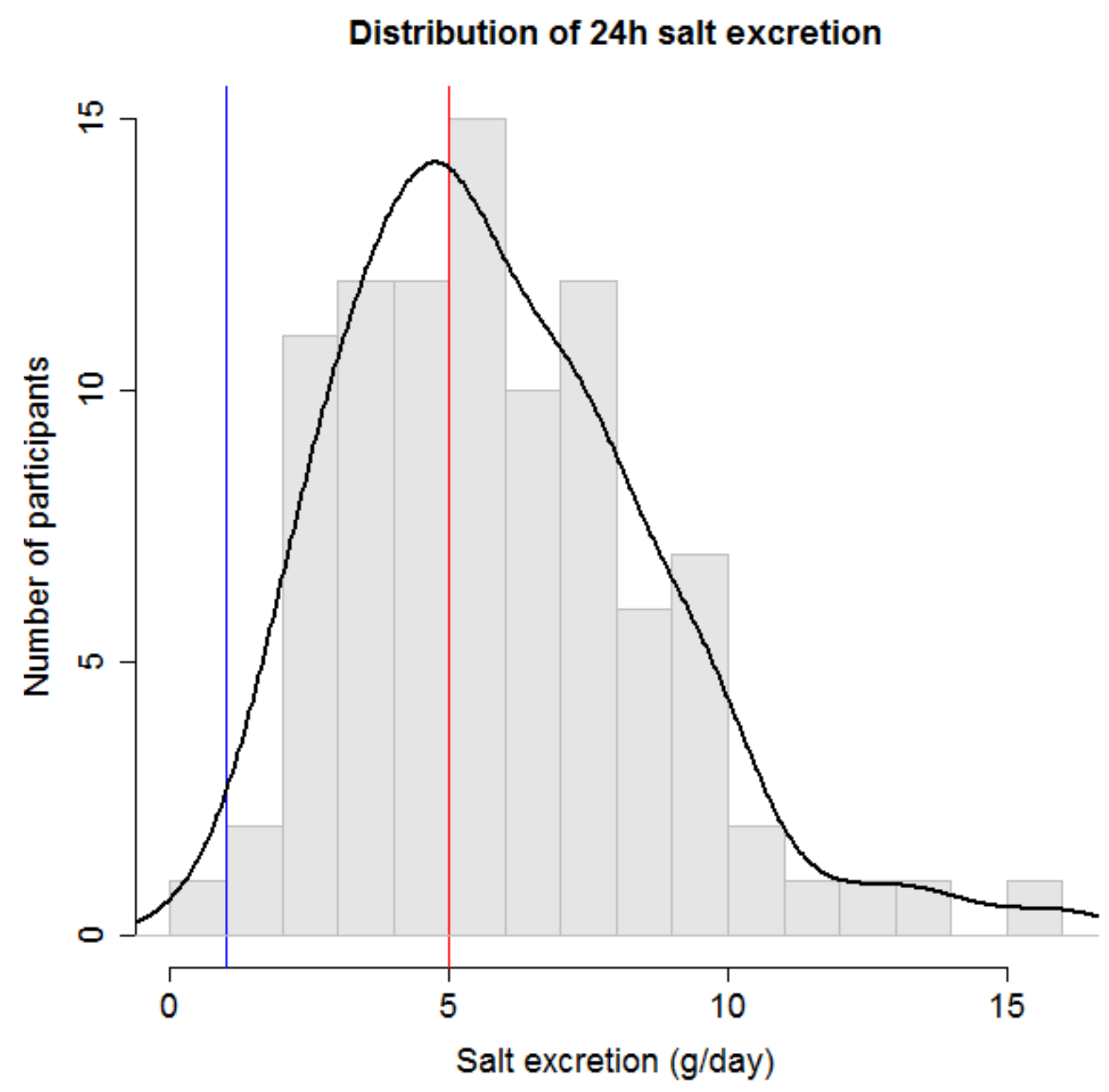


Table 2 Salt excretion (g/day) in children by sub-group (from $24 \mathrm{~h}$ urine collection)

\begin{tabular}{lcccc}
\hline & N & Mean & SD & 95\% CI \\
\hline All & 94 & 5.9 & 2.8 & $(5.3-6.5)$ \\
Sex & & & & \\
Boys & 55 & 6.4 & 3.1 & $(5.6-7.3)$ \\
Girls & 39 & 5.1 & 2.0 & $(4.5-5.8)$ \\
Age & & & & \\
Young (6-11 years) & 65 & 5.5 & 2.6 & $(4.9-6.1)$ \\
Old (12-16 years) & 29 & 6.7 & 3.0 & $(5.6-7.8)$ \\
Weight & & & & \\
Normal weight (BMI z-score $<1)$ & 79 & 6.0 & 2.8 & $(5.4-6.6)$ \\
Overweight (BMI z-score $\geq 1)$ & 15 & 5.4 & 2.6 & $(4.1-6.7)$ \\
Nationality & & & & \\
Swiss (at least one parent is Swiss) & 82 & 5.7 & 2.6 & $(5.1-6.3)$ \\
Foreign (none of the parents is Swiss) & 10 & 7.6 & 3.9 & $(5.2-10.1)$ \\
Parents' highest education level & & & & \\
Tertiary & 61 & 6.2 & 2.6 & $(5.5-6.8)$ \\
Primary or secondary & 31 & 5.4 & 3.1 & $(4.3-6.5)$ \\
Completeness of 24-hour urine & & & & \\
Complete $(\geq 0.1$ mmol creatinine/kg body weight) & 86 & 6.1 & 2.8 & $(5.5-6.7)$ \\
Incomplete ( $<0.1$ mmol creatinine/kg body weight) & 8 & 3.0 & 1.3 & $(1.1-5.0)$ \\
Day of the week & & & & \\
Week-end & 73 & 6.0 & 2.8 & $(5.4-6.6)$ \\
Week & 21 & 5.5 & 2.8 & $(4.3-6.7)$ \\
Physical activity & & & & \\
Low (<15 minutes) & 42 & 5.8 & 2.3 & $(5.1-6.5)$ \\
Moderate-high $(\geq 15$ minutes) & 51 & 5.9 & 2.8 & $(5.2-6.7)$ \\
\hline
\end{tabular}


Fig. 2 Contribution of different food groups to salt intake (from questionnaires)

This figure shows the contribution of different food groups to total salt intake in $\mathrm{g} /$ day and $\%$. The four food groups that provided the most salt to the diet were: 1) cooked (and salted) pastas, potatoes, and rice (1.4 g salt/day, $23.2 \%$ of total salt intake); 2 ) pastries (1.0 g salt /day, $16.3 \%$ of total salt intake); 3 ) bread ( $1.0 \mathrm{~g}$ salt/day, $16.2 \%$ of total salt intake); and 4$)$ cured meats ( $0.6 \mathrm{~g}$ salt/day, $10.3 \%$ of total salt intake). Legend: X-axis: Mean content of salt in foods in $\mathrm{g}$ of salt per $100 \mathrm{~g}$ of food, according to Swiss Food Composition Database [30]. Y-axis: Amount in g per day (left) and percentage (right) of salt contribution from the different food groups to the total salt intake.

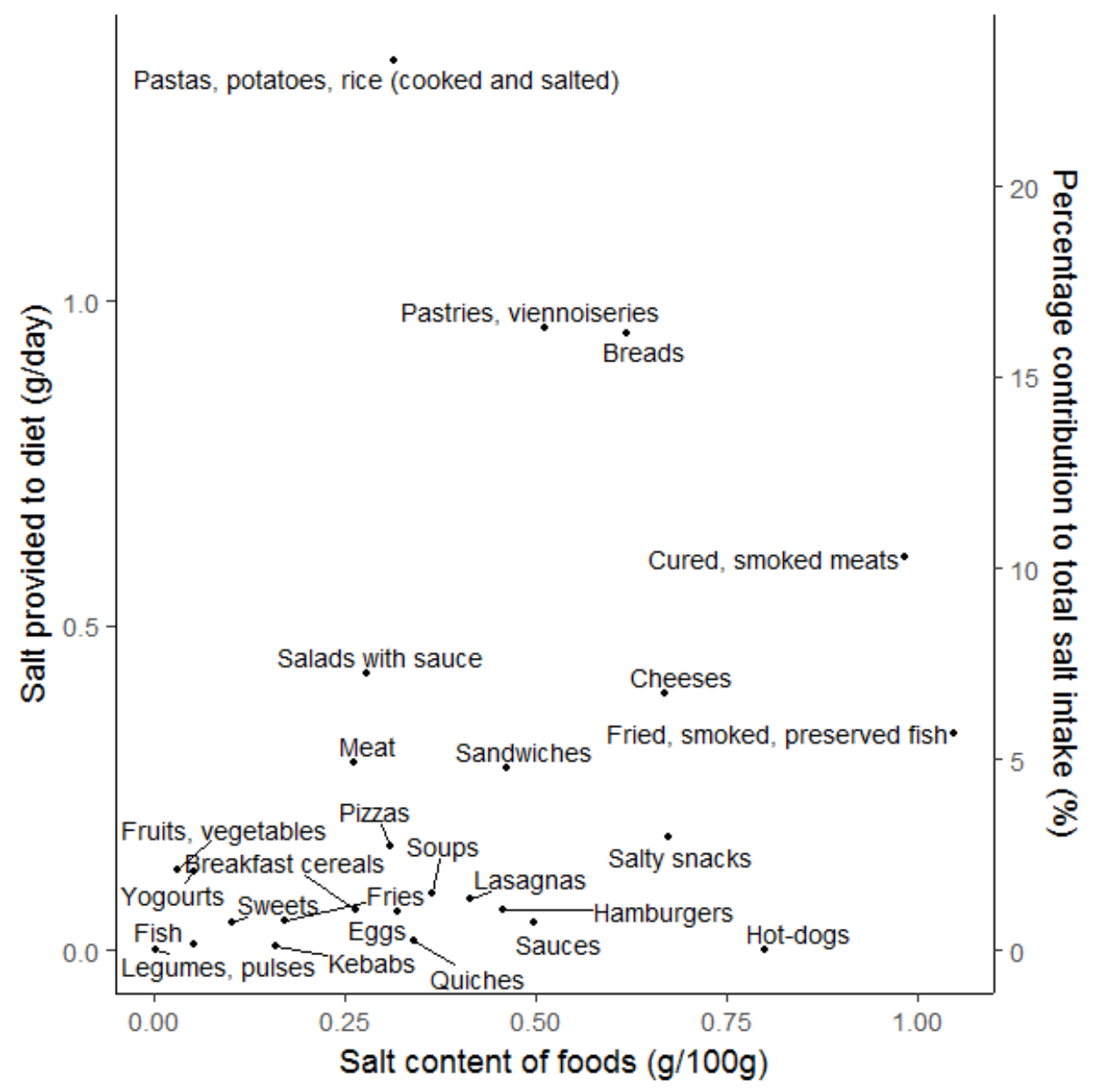

